\title{
China y la construcción de relaciones estratégicas con países de África. Estudio de caso: su postura contradictoria frente al principio de no intervención
}

DiAna ANDREa GÓMEZ DíAZ*

Artículo recibido: 2 de febrero de 2019

Artículo aceptado: $1^{\circ}$ de agosto de 2019

Doi: https://doi.org/10.12804/revistas.urosario.edu.co/desafios/a.7689

Para citar este artículo: Gómez Díaz, D. A. (2020). China y la construcción de relaciones estratégicas con países de África. Estudio de caso: su postura contradictoria frente al principio de no intervención. Desafíos, 32(1), 1-39. https://doi.org/10.12804/revistas.urosario. edu.co/desafios/a.7689

\section{Resumen}

Este articulo tiene como propósito explicar el proceso de construcción de relaciones estratégicas de China con países de África desde el periodo de la Guerra Fría, para posteriormente enfocarse en su postura contradictoria respecto al principio de no intervención en asuntos internos de otros Estados. En primer lugar, se explica el contexto en el que los vinculos sino-africanos se afianzan a partir de la Conferencia Afroasiática de Bandung y luego durante el proceso de Reforma y Apertura chinas, para luego catapultar a la República Popular China como una potencia global, potencia entendida según los postulados de Nicholas Spykman. A lo largo del artículo se

\footnotetext{
* Profesora del Instituto de Estudios Políticos y Relaciones Internacionales (IEPRI), Universidad Nacional de Colombia. Correo electrónico: dagomezdi@unal.edu.co. ORCID: https://orcid.org/0000-0001-8076-3056
} 


\title{
2 I Diana ANdrea Gómez díaz
}

evidencia cómo, mientras China ha venido maximizando su poder, su posición ha sido contradictoria con su defensa del principio de no intervención desde tres perspectivas: su postura en el Consejo de Seguridad como miembro permanente; su intervención en la economía de Estados africanos, inicialmente en la industria petrolifera; y el apoyo militar a Estados en conflicto interno o interestatal en Africa. Esta postura contradictoria se ve reiterada en años recientes con su propuesta globalizadora denominada BRI (Belt \& Road Initiative) y su impacto en paises africanos.

Palabras clave: relaciones China-África, politica exterior china, China y el mundo en desarrollo.

\section{China and the Construction of Strategic Relations with African Countries. Case Study: China's Contradictory Position Regarding the Principle of Non-Intervention}

\begin{abstract}
The purpose of this article is to explain the process of building strategic relations between China and African countries since the Cold Warperiod. Then, the article focuses on Beijing's contradictory position regarding the principle of non-intervention in the internal affairs of other states. In the first part, the text explains the context in which the Sino-African ties have consolidated after the Afro-Asian Bandung Conference and then during the Chinese reform and opening process, in order to catapult the People's Republic of China to global great power status. Here, "great power" is understood according to the postulates of Nicholas Spykman. Throughout the article, it becomes evident how, while China has been maximizing its power, its position has been contradictory with its defense of the principle of non-intervention from three perspectives: its position in the Security Council as a permanent member; its intervention in the economy of African states, initially in the oil industry; and its military support to states in internal or interstate conflict in Africa. This contradictory position is reiterated in recent years with its globalization proposal called BRI (Belt \& Road Initiative) and its impact on African countries.
\end{abstract}

Keywords: China-Africa relations, Chinese foreign policy, China and the developing world. 


\title{
A China e a construção de relações estratégicas com países da África. Estudo de caso: sua postura contraditória frente ao princípio de não intervenção
}

\begin{abstract}
Resumo
Este artigo tem como propósito explicar o processo de construção de relações estratégicas da China com paises da África desde o periodo da Guerra Fria para posteriormente enfocar-se em sua postura contraditória respeito ao princípio de não intervenção em assuntos internos de outros Estados. Em primeiro lugar se explica o contexto em que os vinculos sino-africanos se afiançam a partir da Conferência afro-asiática de Bandung e logo durante o processo de Reforma e Apertura chinesas para depois catapultar à República Popular da China como uma potência global, potência percebida segundo os postulados de Nicholas Spykman. Ao longo do artigo se evidencia como enquanto a China tem vindo maximizando seu poder, a sua posição tem sido contraditória com sua defensa do princípio de não intervenção desde três perspectivas: sua postura no Conselho de Segurança como membro permanente; a sua intervenção na economia de Estados africanos, inicialmente na indústria petrolifera; e o apoio militar a Estados em conflito interno ou interestatal na África. Esta postura contraditória vê-se reiterada em anos recentes com sua proposta globalizante denominada BRI (Belt \& Road Initiative) e seu impacto em países africanos.
\end{abstract}

Palavras-chave: relações China-África, politica exterior chinesa, a China e o mundo em desenvolvimento.

\section{Introducción}

Este artículo tiene como propósito general explicar el proceso de construcción de relaciones estratégicas de China con países de África desde el período de la Guerra Fría, para posteriormente explicar su postura contradictoria respecto al postulado de no injerencia en asuntos internos de otros Estados. En primer lugar, se explica el contexto en el que los vínculos sino-africanos se afianzan a partir de la Conferencia Afroasiática de Bandung y luego durante el proceso de Reforma y Apertura chinos, el cual catapulta a la República Popular China (RPCh) como una potencia global. Su política exterior enfocada 
hacia el mundo en desarrollo tiene a los países africanos como un eje fundamental de su ascenso en el orden mundial. En el proceso de evolución de las relaciones de China con países africanos, se evidencia que la posición de Beijing ha sido contradictoria con su defensa del principio de no intervención desde tres perspectivas: su postura en el Consejo de Seguridad como miembro permanente; su intervención en la economía de Estados africanos, inicialmente en la industria petrolífera; y el apoyo militar a Estados en conflicto interno o interestatal en África. Esta postura contradictoria se reafirma en años recientes con su propuesta globalizadora denominada BRI (Belt \& Road Initiative) y su impacto en países africanos.

Durante la confrontación entre los dos bloques ideológicos de la Guerra Fría, la República Popular China comenzó a reforzar su posición en el tercer mundo como una manera de mantenerse al margen y, hasta cierto punto, por encima de las disputas entre las superpotencias (Kissinger, 2012, p. 406). En tal contexto, este país afirmaba su orientación a establecer alianzas con países del tercer mundo (Hu, 1982, pp. 30-31). El contenido del discurso de los altos líderes chinos era en ese sentido una continuación del que se había generado durante la Conferencia Afroasiática de Bandung, celebrada del 18 al 24 de abril de 1955 , en la cual se discutieron como principales temas la renuencia de las potencias occidentales para consultar con países asiáticos sobre las decisiones que afectaban a Asia; su preocupación por la tensión entre la República Popular de China y Estados Unidos; su deseo de sentar bases más firmes para las relaciones pacíficas de China con Estados Unidos y Occidente; su oposición al colonialismo, especialmente la influencia francesa en el norte de África; y el deseo de Indonesia para promover su causa en la disputa con los Países Bajos en la provincia de Irian Jaya, ubicada al oeste de Nueva Guinea.

En la Conferencia Afroasiática de Bandung, la cual reunió a 29 jefes de Estado de la primera generación poscolonial de líderes de los dos continentes, el objetivo fue identificar y evaluar los problemas mundiales del momento, y desarrollar políticas conjuntas en asuntos exteriores. Un aparte de las palabras del entonces primer ministro chino, Zhou Enlai, al dirigirse a los asistentes fue: "Como comunistas, 
creemos firmemente en el comunismo, y también creemos firmemente en la superioridad del sistema socialista. No obstante, no venimos a difundir ideologías particulares o a propagar los sistemas políticos de algunos países en la Conferencia. Por el contrario, la delegación china viene a buscar puntos en común y a eliminar las discrepancias entre nosotros" (CRI, 2013). He aquí un primer indicio de que la política exterior de la naciente en ese entonces República Popular China se fundamentó en el principio de no intervención en asuntos internos. En Bandung se hizo evidente que se trataba de un discurso ya no solamente enfocado en Asia y África, sino ampliado a más países del tercer mundo (Ministry of Foreign Affairs, Republic of Indonesia, 1955), incluida Latinoamérica. Así mismo, dicho enfoque con el tiempo se mantuvo en la afirmación de una plena autonomía planteada desde Bandung (The Jakarta Post, 2011) por parte de los países en desarrollo. La Conferencia de Bandung del movimiento afroasiático simboliza el surgimiento del tercer mundo como una fuerza motriz en las relaciones internacionales (Bradley, 2010).

China, junto con India y Myanmar (antigua Birmania), había promulgado el año anterior a la Conferencia de Bandung los Cinco Principios de Coexistencia Pacífica, los cuales se supone se han constituido en principios rectores de la política exterior china. Ellos son el respeto mutuo a la soberanía y la integridad territorial, la no agresión, la no intervención en los asuntos internos de otro país, la igualdad y beneficio recíproco, y la coexistencia pacífica.

En la Conferencia de Bandung, estos principios fueron adoptados como los principales fines y objetivos de la política de 29 países en ese entonces, lo que evolucionó posteriormente en la denominada política de no alineamiento. El Movimiento de Países No Alineados (PNA), que surgió en la década de 1960, fue producto de que Estados que habían alcanzado su independencia en los años posteriores, particularmente en África, Medio Oriente y Sudeste Asiático, apoyaron, de una parte, los movimientos de liberación nacional y, de otra, refutaron aliarse a las políticas de las grandes potencias de la Guerra Fría. El movimiento de los PNA fue presentado formalmente en la Conferencia de Belgrado de 1961, cuya agenda fue proyectada por 


\section{I Diana Andrea Gómez díaz}

Figura 1. El primer ministro, Zhou Enlai, en la Conferencia de Bandung, Indonesia, 1955

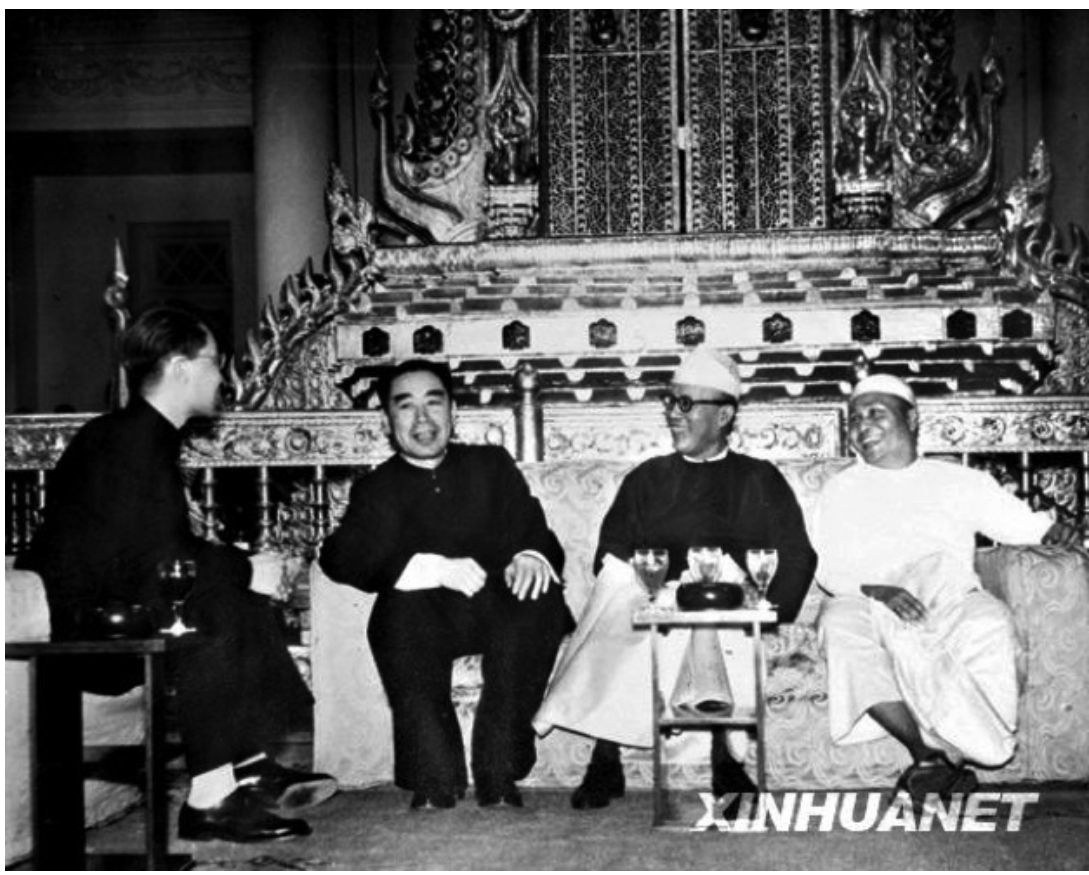

Fuente: The Central People's Government of the People's Republic of China (2009). Recuperado de http://www.gov.cn/test/2009-09/09/content_1412747.htm

líderes de países africanos como Ghana y Mali, además de Cuba e Indonesia. La Conferencia fue influenciada de manera preponderante por el presidente de Egipto, Gamal Abdel Nasser, junto con el mandatario yugoslavo, Josip Broz Tito (Schaufelbuehl, 2015, p. 902). El Movimiento de los No Alineados adoptó los Cinco Principios como sus ejes rectores. Estos también fueron incorporados en las declaraciones pertinentes aprobadas por la Asamblea General de las Naciones Unidas en 1970 y 1974.

En su discurso de conmemoración del $60^{\circ}$ aniversario del compromiso de China con los Cinco Principios, varias décadas después, el presidente chino Xi Jinping recordaba que estos principios se constituyen en la piedra angular de la política exterior china: 
On 28 and 29 June 1954, China issued two joint statements respectively with India and Myanmar, confirming their commitment to these Five Principles in conducting their mutual relations and their respective relations with other countries in Asia and the world. This was a major initiative in the history of international relations and a historic contribution to the building of a new type of just and equitable international relations... Five Principles of Peaceful Coexistence constitute the cornerstone of China's foreign policy (Xi, 2014).

A pesar de la política china de no injerencia en asuntos internos de otros países - en gran medida inspirada en la propia situación con Taiwán como 'provincia rebelde'_-, en la práctica fue evidente el apoyo del gobierno chino a partidos y movimientos políticos en pro de intereses afines a China, así fueran en detrimento de las políticas domésticas de los otros países, y se traducen en posturas no comprometedoras en las votaciones de la Organización de las Naciones Unidas, grandes intereses económicos que comprometen la economía de países africanos y apoyo militar a sectores y grupos ilegales dentro de dichos Estados. En tal sentido, puede afirmarse que China se ha caracterizado desde el período de la Guerra Fría por ser un actor muy dinámico en el sistema internacional, pero contradictorio, logrando maximizar su poder en el sistema internacional, ya que finalmente consiguió más aliados, tanto del primero como del segundo y tercer mundo, tal como lo evidencia la relación que la RPCh ha ido construyendo con países de África, y que demuestra su condición de potencia global.

\section{Notas teórico-metodológicas}

En este artículo se entiende el concepto de 'potencia global' desde la perspectiva del geógrafo Nicholas Spykman (1944), quien determinó diez factores que se constituyen en recursos de poder característicos de las potencias: superficie del territorio, naturaleza de las fronteras, volumen de la población, presencia o ausencia de materias primas, desarrollo económico y tecnológico, potencia financiera, homogeneidad 
étnica, grado de integración social, estabilidad política y espíritu nacional. En tal sentido, y tal como lo sostiene el geopolítico estadounidense Robert D. Kaplan, una Gran China puede estar emergiendo política, económica y militarmente (Kaplan, 2010), como resultado del proceso de construcción de la República Popular China como potencia global. En dicho contexto, los países africanos constituyen una región estratégica para la inserción de grandes potencias globales como China (Alden, et al., 2008) dada la existencia de abundantes recursos naturales y la anuencia de gran parte de los gobiernos africanos para abrir sus puertas a dichas potencias, fundada esta en gran medida en la debilidad del entramado institucional de Estados africanos (Edoho, 2011), y la cual está ligada la naturaleza e identidad de las élites políticas africanas (Obert, 2018). Lo anterior implica estudiar los ejes axiales y las tendencias desarrolladas por China en materia de política exterior hacia países africanos. Por política exterior se entiende aquí, siguiendo a Celestino del Arenal, el estudio de la forma en que un Estado lleva sus relaciones con otros Estados y se proyecta al exterior. Es decir, se refiere a la formulación, implementación y evaluación de las opciones exteriores desde el interior de un Estado consideradas desde la perspectiva del Estado, sin tener en cuenta la postura de otros actores (Arenal, 1990, p. 22).

El presente artículo es producto de una investigación que abarcó aspectos cuantitativos y cualitativos, y fuentes primarias y secundarias, ya que consta de una revisión bibliográfica que permitió, por una parte, ordenar y taxonomizar los hallazgos; y, por otro lado, analizarlos. En primer lugar, se adelantó una investigación bibliográfica de carácter histórico, para lo cual se revisaron textos sobre historia de China como los de Jacques Gernet; y sobre China y el orden mundial como aquellos de Henry Kissinger, con el fin de detectar las percepciones construidas por los ilustrados europeos y norteamericanos sobre China; y, posteriormente, entrevistas y textos de autores del mayor reconocimiento por sus trabajos de investigación sobre la relación de China con África como Chris Alden. La investigación demandó tambien la recolección, sistematización y análisis de diversas fuentes documentales secundarias, como documentos oficiales, informes estadísticos, artículos periodísticos relacionados con China y sus vínculos con África, a las que se suman análisis de coyuntura y de prensa. 


\section{Evolución de la relación entre el dragón chino y el león africano}

Las relaciones entre China y países africanos ${ }^{1}$ a partir del período de la Guerra Fría y desde una perspectiva integral pueden dividirse en tres momentos diferenciados por tendencias marcadas: un primer momento estuvo centrado en el apoyo a las luchas de liberación nacional; un segundo período es definido a partir de iniciativas en el ámbito político doméstico y exterior; y un tercer momento desciende del anterior y se centra en el fortalecimiento de lazos económicos. Las siguientes líneas explican los períodos que han marcado las relaciones entre China y países africanos.

En el período de la Guerra Fría, particularmente en los años de la década de los sesenta y principios de los setenta, la implicación de China en África se caracterizó por una intensa actividad enfocada en el apoyo a luchas de liberación nacional y contra el colonialismo. Los servicios de inteligencia del gobierno chino prestaron apoyo a partidos comunistas en otros países (Kissinger, 2012, p. 123), pero también a grupos insurgentes pro comunistas en otras latitudes. Solo en la década de los sesenta, Beijing respaldó luchas armadas revolucionarias en 23 países (Van Ness, 1970, p. 98). La aproximación de China a países africanos tenía objetivos claros y pragmáticos: 1) ganar simpatía de países africanos a través del apoyo a las luchas de liberación nacional africanas; y 2) conseguir, por medio de esa simpatía, el

\footnotetext{
1 El origen de las relaciones China-África datan del siglo XV durante la dinastía Ming. De las siete expediciones marítimas lideradas por el navegante chino Zheng He, la cuarta (14131415) de ellas fue la primera en arribar a las riberas orientales de África, tras un recorrido de unos 6000 kilómetros, se cree que alcanzando la isla de Zanzíbar. La siguiente expedición (1417-1419) recaló en las costas somalíes y recorrió el mar Rojo. La sexta expedición (14211422) volvería a visitar el golfo Pérsico y el África Oriental, mientras que la última expedición (1431-1433), ya bajo el reinado del emperador Xuande (1425-1435), volvería a visitar la costa oriental africana y las riberas meridionales de Arabia, e incluso fondearía en el puerto más cercano a La Meca, Djeddah. Estas expediciones llegaron a recorrer las costas de los actuales Mozambique, Tanzania, Kenia, Zanzíbar, Somalia, Yibuti, Eritrea, Sudán y Egipto, para establecer vínculos comerciales. Para una perspectiva histórica de las relaciones China-África, ver Gernet (2005, pp. 360 y ss.).
} 
voto de los países africanos a una silla permanente en el Consejo de Seguridad de la ONU, la cual estaba siendo ocupada por Taiwán (1971).

Importantes embarques de armas chinas fueron enviados a países de Asia, África y América Latina. En mayo de 1965, las autoridades del gobierno de Kenia interceptaron un embarque de 75 toneladas de armas chinas que incluían cañones antitanques, morteros, lanzacohetes, minas $y$ ametralladoras pesadas, todo ello formaba parte de un convoy de camiones escoltado por tropas de Uganda y, aparentemente, destinado a los rebeldes del Congo (AP, 1965, citado por Van Ness, p. 88). Van Ness registra la existencia de campos de adiestramiento guerrillero en África, especialmente en el Congo (Brazzaville) y Tanzania, ambos lindando con Kinshasa, sitio de la más activa lucha antigubernamental del continente en los comienzos de 1965. Además, las investigaciones llevadas a cabo desde el derrocamiento del gobierno del líder de la independencia de Ghana, Kwame Nkrumah, en febrero de 1966, revelaron la presencia en ese país de medios de adiestramiento guerrillero dirigidos por chinos y supuestamente establecidos en relación con una vasta red continental clandestina destinada a entrenar exiliados de países africanos tanto independientes como coloniales (New York Times, 1966, p. 20).

Sin embargo, no toda la ayuda financiera a los movimientos revolucionarios se materializaba en armas y entrenamiento militar. Algunos fondos fueron empleados para cubrir los gastos y mantenimiento de los movimientos revolucionarios, o para ayudar a los revolucionarios potenciales, tales como los refugiados watusi en Kenia y Uganda, los cuales fueron despojados de Ruanda, su tierra nativa en África Central (Cooley, 1965, pp. 70-71). El primer ministro de Malawi, Hastings Banda, denunció varias veces que Beijing trataba de comprar su reconocimiento diplomático en la lucha con Taiwán por ser reconocida (New York Times, 1965, p. 8), y tras haber fracasado en ello, estaba ofreciendo ayudas económicas a funcionarios disidentes a cambio de derrocar al gobierno de Malawi (CSM, 1965, p. 2, citado por Van Ness, 1070, p. 131). 
De un activo dinamismo en países de África caracterizado por la injerencia en asuntos internos, y tras la muerte de Mao y de cara al proceso de transición hacia la Reforma y Apertura chinas, la RPCh pasó a un claro abandono de esta región en la década de los años ochenta (Alden, et al., 2008). No obstante, durante este período se habían capitalizado importantes relaciones políticas y diplomáticas con actores estatales y no estatales que facilitaron el estrechamiento de vínculos en los años posteriores.

A partir de 1993 China inicia un nuevo período de relaciones centradas en la importación de petróleo, vínculo que es seguido por una elevación del nivel de las relaciones políticas en 1999, a raíz del inicio de la estrategia going out de la RPCh, que viabilizó la inversión china en el extranjero. Esta política china coincide con una importante coyuntura en África: después de la finalización de varios conflictos, se necesitaba la reconstrucción de economías de países africanos. China necesitaba fuentes de materias primas y de mercados para sus empresas, mientras África requería de socios y recursos financieros. Esta convergencia de intereses y necesidades se canalizó con incentivos para la realización de encuentros del más alto grado en el orden multilateral, lo cual derivó posteriormente en préstamos, créditos de exportación, inversión y ayuda chinos, cambiando el panorama económico de África desde el año 2000, cuando se celebraron las primeras reuniones del Foro para la Cooperación entre China y África (FOCAC). En efecto, el proceso de apertura económica china iniciado en el período de Deng robusteció las relaciones sinoafricanas en una progresión sucesiva hacia un nuevo modelo de relación. En ese contexto, la República Popular China comenzó a considerar seriamente unirse a las instituciones regionales. Inicialmente, los líderes reformistas, como el primer ministro, Zhao Ziyang, querían aprovechar el dinamismo económico en el este de Asia para impulsar la modernización económica china. Más tarde, las élites gobernantes del Partido Comunista chino también comenzaron a ver la participación institucional como una parte ineludible de su diplomacia relacionada en gran medida con una preocupación central: la dominación de Estados Unidos y Japón en la región. Desde mediados de la década de 1990, China demostró un activismo sin 
precedentes y un creciente liderazgo en las iniciativas multilaterales inter y extrarregionales. El cambio se hizo más evidente tras el regreso al unilateralismo de Estados Unidos después de los ataques terroristas del 11 de septiembre de 2001 (Deng, 2008, pp. 200-201).

La República Popular China bajo el discurso de la igualdad se afianzó en la defensa de la soberanía de todos los Estados tanto "grandes y pequeños, occidentales y no occidentales, ricos y pobres, democráticos y autoritarios, (sea que) cada uno siga su propio sistema, (sea que) sus métodos se adapten a los estándares occidentales o no" (Booth \& Trood, 1999, p. 104). Desde dicha postura, China abría las puertas de su política exterior a todos los colores del espectro político y los sistemas económicos, y en esa medida encontró eco en numerosos Estados, especialmente en el mundo en desarrollo. Esto le significó dos tipos de acción: la primera, centrada en el orden multilateral, consistió en enfocar el discurso político chino según el cual la RPCh se erige como una "potencia responsable", 2 lo que inició con un activismo sin precedentes desde escenarios de primer orden como las Naciones Unidas. La otra, enfocada en el ámbito bilateral, consistió en establecer en la práctica relaciones con numerosos Estados de Asia, África y América Latina, incluidos aquellos catalogados por la comunidad internacional como parias. Tal es el caso en África de Sudán, Zimbabue, Angola y Chad, países anatematizados por los Estados occidentales en razón de sus deficiencias en materia de respeto a los derechos humanos y prácticas de "buen gobierno" (Alden, 2008, p. 68). Así, la postura política abierta de China no encontró obstáculos —ni aún hoy_ para sus intereses económicos en África.

El año de 1993 marcó un giro trascendental en los vínculos económicos sino-africanos cuando China pasó de ser exportador a importador de petróleo para sostener el ritmo trepidante de su economía (Zweig

\footnotetext{
2 El concepto de "potencia responsable" aparece en el discurso político de los altos líderes chinos desde que la República Popular China (RPCh) comienza a autodenominarse como “大国” (Dàguó), o país potencia (se traduce literalmente como "gran país"), durante la presidencia de $\mathrm{Hu}$ Jintao. Para un análisis sobre China como potencia responsable, ver Scott (2010, pp. 72-96).
} 
\& Jianhai, 2005). Un alto funcionario chino del Ministerio de Territorio y Recursos, Wang Jia Shu, describía así la nueva geopolítica del petróleo: "El objetivo geopolítico fundamental de China desde un punto de vista estratégico es: concentrar los ataques en los países vecinos, firmeza en Oriente Medio, desarrollo en África" (Wang, 2004, p. 17). De ahí que la actual estrategia china de implicarse con los países en desarrollo y garantizar recursos para su crecimiento doméstico mediante acuerdos intergubernamentales — habida claridad de que los acuerdos bilaterales son más flexibles que los multilaterales en los que deben seguirse las normas y principios - 3 es fruto de dicho reconocimiento, así como de la valoración de los riesgos derivados de la inestabilidad política de los países proveedores de petróleo en Oriente Medio. Todas las motivaciones anteriores, inspiradas fundamentalmente en la intervención estadounidense y posterior ocupación de Irak a partir de 2003, además de las diásporas a raíz del programa nuclear iraní, son las razones por las cuales África cobró mayor relevancia en los cálculos estratégicos de China.

Para Beijing los países africanos representaron un socio natural para llevar a cabo la estrategia china denominada going out, iniciada en 1999 para fomentar la inversión directa hacia el exterior. De ahí que desde octubre de ese año el presidente Jiang Zeming elevara la relación con África al más alto nivel: le propuso al secretario general de la Organización de la Unidad Africana — entidad predecesora de la Unidad Africana (UA) - , Salim Ahmed Salim, encuentros periódicos de nivel ministerial entre China y los Estados africanos (Anshan, 2006, p. 11). Así, la primera conferencia ministerial del FOCAC), designada para facilitar las consultas y ensanchar los lazos entre China y los países africanos, se realizó del 10 al 12 de octubre del año 2000. Allí Beijing inició su programa de ayuda a África, comprometiéndose con un aporte de 10 millones de renminbis para los países más pobres de este continente (Deng, 2008, p. 229).

En la segunda conferencia del Focac, efectuada en Adis Abeba en diciembre de 2003, China anunció la exención de tarifas a ciertos

3 En los acuerdos bilaterales, los socios pueden ajustar las normas a los intereses mutuos. 
productos de los países más atrasados de África y simplificó los trámites para que los ciudadanos chinos pudieran viajar más fácilmente a aquellos países (Xinhua, 2003). Los vínculos económicos alcanzaron un nuevo estadio particularmente a partir de 2006 con la apertura de numerosos lazos comerciales y de inversión china en países de África. En efecto, en noviembre de 2006, el presidente Hu Jintao anunció en el marco de la tercera conferencia de la Focac la entrega de 10 mil millones de dólares para apoyar el desarrollo de África, el comercio bilateral y las inversiones chinas (Hu, 2006, p. 3). A diferencia del énfasis de los países de Occidente en los asuntos concernientes a los derechos humanos, la RPCh se enfocó en el comercio con el apoyo del gobierno y en la expansión de la inversión china. Así mismo, en enero de 2007, un satélite comercial fue enviado al espacio, lo que reflejó la consolidación de los lazos económicos sino-africanos en sectores de alta tecnología (China Civil Engineering Construction Corporation, 2007).

En 2009 China se convirtió en el mayor socio comercial del continente africano, superando a Estados Unidos (Park, et al., 2016, p. 1). Esta tendencia ha estado acompañada de préstamos chinos financiados por la banca china y multilateral. El Banco de Desarrollo Africano, el East African Development Bank y el South Africa's Standard Bank aceptaron ofertas del gobierno chino para desarrollar inversiones en diferentes sectores económicos. Los créditos chinos, comparados con las exigencias de la banca y las entidades multilaterales occidentales, se otorgan de manera más flexible, con menos riesgos, más enfocados en las necesidades locales y con más receptividad por parte de las clases dirigentes africanas (China in Africa Digest, 2007). No obstante, también han dejado serias dudas en cuanto al nivel de transparencia. ${ }^{4}$ Así mismo, China impone condicionalidad económica al vincular casi todos sus proyectos de ayuda y préstamos a la construcción de infraestructura por parte de compañías chinas y al uso predominante

\footnotetext{
4 Autores como Frances Pontemayor y Stephan Mothe (2016) destacan las notables diferencias entre las actividades de instituciones chinas de financiamiento centradas en África y sus contrapartes occidentales.
} 
de materiales chinos. Empero, esta práctica ha sido común en otras grandes potencias como Gran Bretaña, Francia y Estados Unidos.

Los estudios más recientes demuestran que China es la mayor fuente de préstamos bilaterales de África y un importante proveedor de ayuda equivalente a la de la Organización para la Cooperación y el Desarrollo Económicos (OCDE), aunque muy por detrás de la Unión Europea y Estados Unidos (Shinn, 2019, p. 1). No obstante, China ha conferido una nueva dinámica económica a los países africanos, obligando por la fuerza de los hechos a que los tradicionales socios europeos y Estados Unidos reevalúen su relación con países africanos, ante el riesgo de perder más terreno ante la emergencia china.

\section{China en la Organización de las Naciones Unidas}

A pesar de que el número de organizaciones internacionales a las que China se adhirió entre 1979 y 2002 ascendió de manera exponencial de 34 a 202 (People's Daily, 2002), el gobierno chino se hizo consciente del hecho de que sería políticamente imprudente aparecer públicamente como una activa fuerza promotora del cambio en el orden internacional. Del "ascenso pacífico" de China (Zheng, 2005) pasó a un discurso más neutral y menos confrontador, siendo el "desarrollo pacífico" el lema de gobierno (State Council, 2005). Del mismo modo, mientras que, en el informe del presidente Jiang Zemin presentado durante el $16^{\circ}$ Congreso del Partido Comunista de China en 2002, se refirió a "impulsar un mundo multipolar" (Jiang, 2002), su sucesor, el presiente Hu Jintao aludió a que el proceso de multipolaridad "se estaba profundizando" (Garver, 2016, p. 547). Sin embargo, a pesar de esta búsqueda de un perfil bajo, el tono de los discursos de los altos líderes chinos ha cambiado y el gobierno chino no ha evitado tomar firmes decisiones de política internacional en los últimos años. En ningún otro contexto es esto más evidente que en la ONU, y en especial dentro del Consejo de Seguridad.

Existen cuatro razones para estudiar el comportamiento de China en el Consejo de Seguridad como el mejor indicador disponible de su 
enfoque hacia la construcción de una potencia global, pero también como indicador de su afianzamiento de las relaciones con países en desarrollo para consolidar alianzas estratégicas, como se evidencia con África. La primera razón para estudiar su comportamiento en el Consejo de Seguridad es estructural y se relaciona con el hecho de que, pese a las críticas a dicha organización, la ONU sigue siendo una institución supraestatal dotada de un poder significativo y una cierta legitimidad global (Foot, 2003). Dado que la actividad específica del Consejo de Seguridad de las Naciones Unidas (UNSC, por su sigla en inglés) se considera que puede incidir en la soberanía nacional (a la luz de las disposiciones contenidas en el capítulo VII de la Carta de las Naciones Unidas y como consecuencia de la reciente evolución de las normas internacionales en cuanto a la legitimidad de la intervención) y debido a que el respeto de la soberanía es un tema muy sensible para el gobierno de Beijing, la conducta de China en el UNSC puede tomarse como un indicador significativo de sus actitudes generales hacia la gobernanza global. En efecto, para la RPCh ser miembro del UNSC es un espacio idóneo para tener gran libertad y movilidad teniendo en cuenta el esfuerzo constante realizado especialmente por los cinco miembros permanentes ${ }^{5}$ para excluir a la ONU de su importante participación en los conflictos en los que tienen intereses de seguridad directos. Y en el caso chino, Taiwán es uno de los ejemplos más evidentes. Así mismo, la postura constante de Beijing respecto a los conflictos internacionales, especialmente fronterizos, ha sido la vía bilateral, lo cual encaja con las acciones que los miembros del Consejo de Seguridad han emprendido en casos de conflicto, donde las decisiones no son consensuadas con todos los miembros de la ONU.

\footnotetext{
5 También es denominado P5 e incluye los siguientes cinco gobiernos: China, Francia, Rusia, Reino Unido y Estados Unidos. Ha habido llamadas frecuentes para reformar la composición del Consejo de Seguridad de la ONU, la mayoría de las cuales incluyen la aceptación de Japón, Alemania, India y Brasil (conocido como el G4) como miembros permanentes. Japón y Alemania son el segundo y tercer mayores contribuyentes al presupuesto de la ONU, respectivamente; India es una potencia nuclear, la mayor democracia del mundo y el segundo país más poblado. Brasil es la nación más grande y más poblada de América Latina.
} 
En segundo término, para China el tener una silla en el UNSC se constituye en el escenario por excelencia para difundir un discurso amistoso, concertado y pacifista en un escenario multipolar (PRC, 2005), al que se suma la visión de que China ahora está a favor de un enfoque más proactivo en los asuntos del mundo, haciendo de la ONU el foro multilateral más relevante de la política internacional para que China sea observada.

En tercer lugar, la conducta de la RPCh en el Consejo de Seguridad y, en especial, su comportamiento electoral han demostrado que China ha desarrollado una postura relativamente peculiar vis-à-vis los otros miembros permanentes del Consejo. En concreto, tres tendencias son dignas de mención: la República Popular China ha efectuado el menor número de vetos, ha hecho un uso frecuente de abstenciones y de forma sistemática ha empleado cuatro opciones de voto en oposición a lo establecido, cuando lo instituido son tres: voto a favor, abstención y uso del poder de veto. La RPCh ha agregado una que utiliza a menudo: la opción de no participar en la votación (Breslin, 2010, p. 116). China ha demostrado así mayor preferencia por abstenerse en lugar de hacer uso del veto sobre las resoluciones relacionadas con los intereses chinos (Global Policy Forum, 2008).

En cuanto al uso de su poder de veto, desde 1971, la República Popular China lo ha empleado solo nueve veces (ONU, 2015), mostrando gran moderación si se compara con las 103 de Rusia y los 79 casos en los que Estados Unidos lo ha ejercido. ${ }^{6}$ China ha mostrado tradicionalmente una considerable aversión al empleo de lo que puede ser descrito como la más poderosa y visible arma diplomática a su disposición. Después de haber criticado vehementemente el poder de veto como instrumento moralmente corrupto de la política, los dirigentes chinos han estado claramente no dispuestos a hacer mucho uso de él, mientras que su discurso en favor de la paz ha sido un factor

\footnotetext{
6 Nótese que mientras Rusia hizo uso de él de manera más frecuente en el pasado, Estados Unidos desde 1972 ha utilizado su poder de veto más que cualquier otro miembro permanente.
} 
que ha contribuido a la construcción de su reputación internacional (Tieh, 2004, p. 22).

En cuarto lugar, después de la implosión de la URSS, la República Popular China ha demostrado su deseo de no ser percibida como aislada frente a las resoluciones propuestas por las potencias occidentales: la mayoría de las decisiones recientes vetadas por China llevaron a Rusia también al 'no'. Esta tendencia demuestra, a su vez, la creciente consonancia en cuanto a las posturas de China y Rusia, lo que las vincula más estrechamente en nuevos escenarios internacionales como el BRICS y la Organización de Cooperación de Shanghai.

Pero lo que ha impulsado en gran medida la actitud cauta de China en escenarios multilaterales con las Naciones Unidas a la cabeza ha sido el aumento de la inversión china en los países en desarrollo y el interés para que la comunidad internacional, en particular países de Occidente, la consideren como un socio y no como una amenaza (Fok, s. f.). El apoyo de China al mundo en desarrollo, específicamente desde fines de la década pasada, ha sido contundente. Como lo expresó el presidente Hu Jintao ante la Organización de las Naciones Unidas el 23 de septiembre de 2009 en Nueva York:

As a responsible and major developing country, China has always made common development an important aspect of its foreign policy. We have made great effort to provide support and assistance to other developing countries, and fulfilled our commitment under the UN Millennium Declaration. So far, we have given assistance to more than 120 countries, cancelled debts for 49 heavily-indebted poor countries and least developed countries, and extended zero-tariff treatment to commodities from over 40 least developed countries (PRC, 2015, p. 4).

Las cifras han aumentado considerablemente: China prestó alrededor de $\$ 125$ mil millones al continente africano de 2000 a 2016, según datos de la Iniciativa de Investigación China-África en la Escuela de Estudios Internacionales Avanzados de la Universidad Johns Hopkins de Washington (SAIS-CARI, 2018). El presidente Xi Jinping 
en septiembre de 2018 anunció la cancelación de la deuda existente de las naciones más pobres del continente africano con China (Al Jazeera, 2018).

La RPCh ha trabajado paralelamente en el financiamiento de los vínculos bilaterales con los países africanos mientras ha ampliado su diplomacia multilateral al continente, en particular al lanzar el Foro para la Cooperación entre China y África (Focac), la conferencia interministerial ofrecida por China y África cada tres años desde su creación en el año 2000. Pero ha sido a nivel diplomático, específicamente en el contexto de los foros multilaterales, donde China se ha hecho a una gran ventaja con sus aliados africanos: la tendencia al 'voto en bloque' de los países africanos, los cuales suman 54 votos en escenarios como la Organización de las Naciones Unidas y sus agencias, que se constituye en un muy valioso capital político por ser disputado. En efecto, el primer resultado concreto de una política exterior china que involucró desde las décadas de los cincuenta y de los sesenta a los países africanos en su espectro se dio en 1971 con el apoyo de Estados africanos a la República Popular China para convertirse en la representante legítima de China en las Naciones Unidas, en reemplazo de la República de China (Taiwán), como se reflejó en la Resolución 2758 de la Asamblea General de las Naciones Unidas. Se trató de un apoyo que fue decisivo: 26 votos a favor procedentes de África, de un total de 76 votos a favor.

Así mismo, los gobiernos africanos han demostrado ser un apoyo sólido para China fundamentalmente cuando ha sido cuestionada y los gobiernos de África han apoyado el bloqueo de resoluciones de la Comisión de Derechos Humanos de la ONU para condenar los abusos de China en dicho terreno. También ha sido apoyada cuando la RPCh ha requerido contar con votos para asuntos tan importantes como la decisión en el Comité Olímpico Internacional de conceder a Beijing ser la sede de los Juegos Olímpicos de 2008.

El interés chino en África se explica, en primer lugar, por una motivación de fondo relacionada con la política doméstica de la RPCh desde la década de 1950: la necesidad de desplazar las relaciones de Taiwán 
con el continente africano. Este ha sido un elemento sustancial por el cual la RPCh ha desarrollado muy diversas estrategias con miras a ganar espacio en el terreno diplomático, en detrimento de la diplomacia de Taiwán (Taylor, 2002). En el marco de dicha competencia y con el objeto de obtener beneplácito por parte de los gobiernos africanos, China ha participado en proyectos de gran envergadura, tales como la construcción de edificios públicos, lo que ha resultado en la realización de acuerdos y contratos con los gobiernos de los países africanos. Ejemplo evidente de ello han sido las obras de ampliación del Parlamento de Uganda, la construcción de oficinas nuevas en los ministerios de Asuntos Exteriores de Angola y Mozambique, los palacios presidenciales en Harare (Zimbabue) y Kinshasa (República Democrática del Congo), además de estadios en Sierra Leona y en la República Centroafricana (Alden, 2008).

Durante las cumbres de más alto nivel que involucran directamente a China con el continente africano, como la Cumbre del Foro para la Cooperación entre China y África (Focac), suelen reunirse los altos líderes de ambas zonas del mundo, incluyendo aquellos acusados por entidades internacionales de primer nivel. En septiembre de 2018 en Pekín se reunieron altos dignatarios acusados por tribunales de justicia internacional, como el presidente de Sudán, Omar al Bashir, quien ha estado en el poder durante casi 30 años, y es buscado por la Corte Penal Internacional (CPI) por crímenes de guerra, asesinatos y persecución en la provincia de Darfur (Sudán) entre 2003 y 2008. $\mathrm{El}$ argumento del gobierno chino es que "las fuerzas extranjeras" no deberían interferir en los asuntos internos de Sudán. China no es parte en el tribunal y "siempre ha tenido reservas sobre la acusación y orden de arresto de la Corte Penal Internacional contra el presidente de Sudán” (Reuters, 2018). La RPCh ha demostrado que está dispuesta a utilizar sus relaciones diplomáticas con regímenes problemáticos $\mathrm{y}$, a la vez, ha buscado mostrar una actitud más cooperativa con la ONU, lo cual le otorga mayor estatus internacional. Es así como China ha seguido fortaleciendo su liderazgo en el Consejo de Seguridad y su papel en la comunidad internacional. 


\section{Los intereses económicos de China en África}

\section{El potencial económico de los países en desarrollo}

En el escenario de la economía global, además de China, otros países en desarrollo han sobrepasado desde la pasada década el ritmo de crecimiento de las economías avanzadas. Tres razones subyacen a esta realidad. Una de ellas es que aquellos países en desarrollo han desplegado un continuo y estable potencial de crecimiento económico, con lo cual algunos de ellos han sido catalogados como economías emergentes. La otra razón es el crecimiento lento de las economías industrializadas. Así lo demuestran las cifras de organismos como el Banco Mundial (BM), que para el año 2030 pronostica que los países en desarrollo tendrán una contribución equivalente a las dos terceras partes del crecimiento mundial (sería del 40\%, si se excluye a China), representarán la mitad de la producción del planeta (30\%, omitiendo a China) y serán el principal destino del comercio mundial. Las más grandes potencias globales actuarán como polos de crecimiento adicionales en una economía mundial multipolar (World Bank, 2013, pp. 6-7). ${ }^{7}$ La figura 2 asílo evidencia también al mostrar que las potencias emergentes están configurando ese nuevo orden mundial multipolar.

Una tercera razón es que, si bien el mundo en las últimas dos décadas ha presenciado la transición que ha efectuado China en el sentido de pasar de ser un país receptor a uno proveedor de ayuda exterior, también es cierto que la financiación oficial china ha impulsado el desarrollo económico y social de los países receptores, ha fortalecido las relaciones políticas bilaterales y viene ensanchando los lazos económicos. Y esto ha impactado de manera contundente la economía de los países en desarrollo. El tipo de financiación y cooperación proporcionados por China se utiliza para lograr múltiples objetivos, no solo ayudar al desarrollo económico de los países receptores, sino

\footnotetext{
El Banco Mundial proyecta que, como consecuencia del rápido y continuo crecimiento de las economías emergentes, tendrá lugar una expansión sin precedentes de la clase media global. Se estima que de menos de 1,8 mil millones de personas en 2009 se ascenderá a alrededor de 5 mil millones en 2030 (World Bank, 2013).
} 
Figura 2. Las diez economías emergentes en 2016 y 2050

Emerging markets will dominate the world's top
$\mathbf{1 0}$ economies in $\mathbf{2 0 5 0}$ (GDP at PPPS)
\begin{tabular}{cccc} 
& 2016 & 2050 \\
China & 1 & 1 & China \\
\hline US & 2 & 2 & India \\
\hline India & 3 & 3 & Us \\
\hline Japan & 4 & 4 & Indonesia \\
\hline Germany & 5 & 5 & Brazil \\
\hline Russia & 6 & 6 & Russia \\
\hline Brazil & 7 & 7 & Mexico \\
\hline Indonesia & 8 & 8 & Japan \\
\hline UK & 9 & 9 & Germany \\
\hline France & 10 & 10 & UK \\
\hline E7 economies & & G7 economies
\end{tabular}

Fuente: IMF for 2016 estimates, PwC analysis for projections to 2050 (2017).

también para la promoción de sus exportaciones, asegurando los flujos de los recursos naturales, y la mejora de las relaciones diplomáticas.

La práctica actual de la RPCh de ofrecer ayuda al desarrollo, con requisitos mínimos en los préstamos por lo menos para el corto plazo, y con condiciones competitivas para los créditos destinados a la exportación, se asemeja a las características de la relación asimétrica de los países industrializados con el tercer mundo. No obstante, el éxito de China como potencia ha impactado hasta cierto punto de manera positiva el fortalecimiento del desempeño de los países en desarrollo. Esto se refleja en la participación de la RPCh en el producto interno bruto (PIB) mundial, que mientras en 1990 era del 1,5\%, 20 años después, en 2010, ya era del 9,5\%, y para el año 2015 ya se posicionaba como el segundo país del mundo con el mayor PIB, por debajo de Estados Unidos, con un total de 10866444 millones de dólares (World Bank, 2016). Empero, su incremento no fue el único: la participación de otros países en desarrollo en el PIB mundial aumentó del 15\% al 22\% durante el mismo período. Si bien la competencia creció para los países exportadores de altos ingresos, el 
incremento de las importaciones en los países en desarrollo también creó nuevas oportunidades.

En una mirada prospectiva, el ritmo de avance en los países de ingresos altos es altamente probable que continúe siendo ostensiblemente menor que en los países en desarrollo. Estos últimos registran actualmente un crecimiento del PIB dos veces más rápido que el de los países industrializados. Una de las proyecciones sostiene que el crecimiento promedio del PIB en los países de ingresos altos oscilará entre el 1,6\%, en un escenario de bajo crecimiento, al 2,9\%, en un escenario de alto crecimiento (World Bank, 2013, p. 368). Otras más recientes arguyen que el crecimiento de los países del G7 será en promedio del 1,6\% (Canadá, Francia, Alemania, Italia, Japón, Reino Unido y Estados Unidos). Este crecimiento será impulsado por los mercados emergentes y los países en desarrollo, con las economías del E7 (Estados emergentes) a la cabeza: China, India, Indonesia, Brasil, México, Rusia y Turquía, creciendo a una tasa promedio anual de casi el 3,5\% en los próximos 34 años (PWC, 2017, p. 6). Como se muestra en la figura 3, las economías del E7 podrían abarcar casi el $50 \%$ del PIB mundial para 2050, mientras que la participación del G7 se reduce a solo un poco más del $20 \%$.

Figura 3. Cambio proyectado en la distribución del PIB mundial de 2016 y 2015

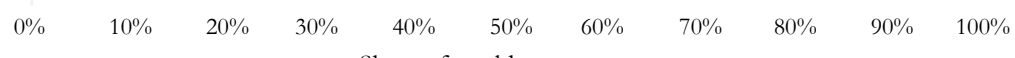

Fuente: PwC (2017). The world in 2050. The long view: how will the global economic order change by 2050? UK: Pricewaterhouse Coopers, p. 6. 
Desde el punto de vista económico, es claro que los competidores de las empresas chinas estarán predominantemente en países en desarrollo, pero también, y cada vez más, los mercados para los productos chinos estarán allí en los países en desarrollo. Desde la perspectiva política, la relación construida a lo largo de los últimos años entre China y los países en desarrollo habrá tenido sus frutos, ya que sus grandes aliados del mundo en desarrollo seguirán siendo estos países, algunos de ellos cada vez más consolidados como economías emergentes. Estas proyecciones indican, por ende, que los países en desarrollo en 2030 se habrán constituido como la fuerza dominante en la economía mundial. Ellos serán los responsables de dos tercios del crecimiento global, mientras solo un tercio será originario de los países de altos ingresos actuales. En tal contexto, los Estados africanos se perfilan como prometedoras economías emergentes. África tuvo 6 de las 10 economías de más rápido crecimiento en 2018, y, según el Banco Mundial, la lista está liderada por Ghana, seguida por Etiopía y Costa de Marfil, con Senegal y Tanzania ocupando el cuarto y quinto lugar, respectivamente (World Bank, 2018, p. 143).

Los países que no hacen un uso intensivo de recursos también pueden desarrollar su economía a un ritmo sólido, ayudado por un continuo crecimiento de la inversión. El crecimiento en África subsahariana se estima aumente alcanzando un promedio de 3,7\% en 2020-21, destacándose Etiopía con un crecimiento proyectado del PIB en 2019 del 8,8\% anual, Ruanda con el 7,8\% y Ghana con el 7,3\%, al igual que Costa de Marfil (World Bank, 2019, p. 109). Estas cifras coinciden en mostrar la potencialidad económica de países africanos, dado el crecimiento estable y continuo de sus economías a lo largo de la década presente. Lo anterior se confirma con el proceso veloz de urbanización que está teniendo lugar en dicho continente y que está desplazando en ritmo de urbanización a América Latina, la subregión de más alto nivel de urbanización del mundo.

Como reflejo de sus ambiciones globales en el siglo XXI, la RPCh ha desarrollado una diplomacia robusta en el mundo en desarrollo más allá de su vecindario. En todos los lugares donde ha establecido vínculos, China está desarrollando lazos sustantivos diseñados para 
impulsar su estatus global, y donde ha sido más evidente su presencia dentro del mundo en desarrollo ha sido en África.

\section{Evolución de la relación económica China-África}

Alrededor del 85\% de las exportaciones de África a China están constituidas por materias primas (Shinn, 2019, p. 3). Los intereses chinos en países africanos se centran en la explotación de recursos energéticos, mineros, forestales, pesqueros, agrícolas y en industrias de la construcción. De acuerdo con las estadísticas oficiales de China, en los últimos años, los flujos de inversión extranjera directa (IED) a África han sido de alrededor de 3 mil millones de dólares anuales. A partir de 2015, las acciones de IED de China en África se invirtieron en los siguientes sectores: minería y petróleo (28\%), construcción ( $27 \%)$, manufactura $(13 \%)$, servicios financieros $(10 \%)$, investigación científica y servicios de tecnología (4\%), y otros sectores (18\%) (Sun, Jayaram \& Kassiri, 2017, pp. 29-30).

El petróleo encabeza los productos de exportación de África hacia China; el segundo lugar lo ocupa la madera, siendo Liberia, Gabón y Guinea Ecuatorial los mayores exportadores; y hasta países con recursos naturales escasos, como Etiopía, han visto multiplicado su comercio (World Bank, 2013, p. 368). La figura 4 muestra el crecimiento de las exportaciones de China a África y las importaciones desde África a China durante el período 2005-2015.

El primer y gran compromiso chino en África lo constituye desde la década de los noventa la inversión en la industria petrolera de Sudán, después de que las compañías occidentales abandonaron el país en medio de las tensiones por la violación de derechos humanos y la inestabilidad política. La RPCh, a través de la Corporación Nacional de Petróleo de China (PetroChina), convirtió a este país africano en un exportador neto de petróleo y en el principal abastecedor de este recurso para China. Las multinacionales chinas efectuaron inversiones similares para el consumo interno chino en Nigeria, Angola y Gabón, así como la compra de participaciones en los campos de explotación del gas natural en Argelia. Dichas inversiones se vincularon 
Figura 4. Comercio total de China con África 2005-2015

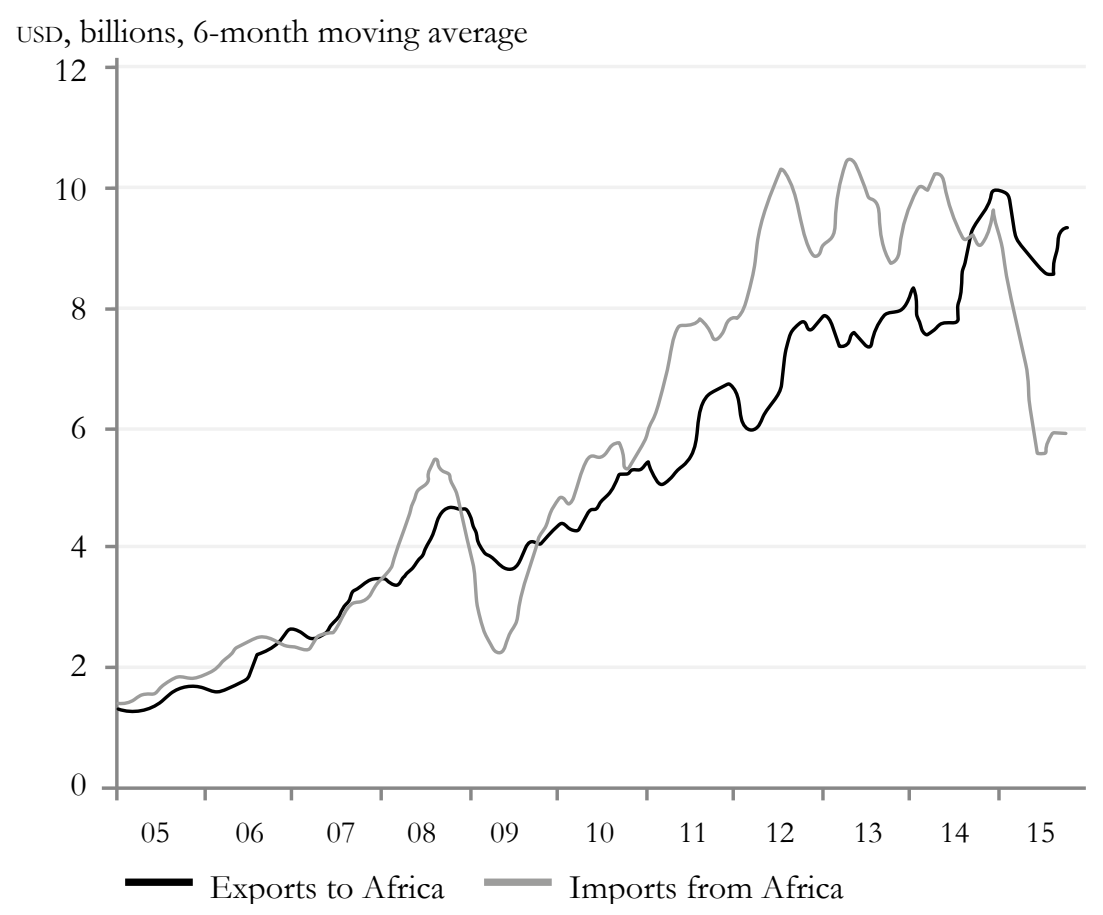

Fuente: Fathom Consulting (2015). Recuperado de http:/ / uk.businessinsider.com/ fathom-report-onchinese-trade-with-africa-2015-12

desde un principio con proyectos de construcción e infraestructura, especialmente carreteras e instalaciones portuarias. Estas iniciativas cumplen el doble propósito de crear un gran atractivo a los ojos de los gobiernos africanos y generar mayor eficiencia a las empresas chinas instaladas allí. No obstante, son de resaltar las formas como se otorgan los créditos y los escenarios para la cancelación de las deudas chinas a los países africanos. Los pagos de los préstamos se basan en los recursos minero-energéticos (petróleo en su mayoría) africanos que oscilan de acuerdo con las fluctuaciones de los precios internacionales del crudo. En las renegociaciones, los países africanos comprometen a China en la construcción de infraestructuras vitales, principalmente puertos y medios de comunicación. Esto está sucediendo en países como Nigeria, Sudán, Kenia, Zambia y Burkina 
Faso, lo que genera preocupación acerca de la independencia respecto a la soberanía nacional.

En medio de este panorama, los lazos comerciales y financieros de China en África se fueron consolidando a fines de la primera década de 2000 de múltiples maneras: en Guinea Ecuatorial y Liberia con la explotación maderera, en Tanzania con grandes monocultivos de algodón y agave, en Botswana con la renovación de la infraestructura en transporte, mientras en Zambia y Kenia con inversiones en la producción textil, así como en Djibuti y Namibia con la instalación de sofisticados sistemas de comunicación (Deng, 2008, pp. 21-22).

Las empresas chinas se han caracterizado no solo por la presencia de multinacionales, también empresas medianas y pequeñas, y todas con un común denominador que desbancó a cualquier competidor occidental y no occidental: vinculando ciertos proyectos locales a sus inversiones y ofreciendo bajos costos laborales y largas jornadas de trabajo, aportando sus propios trabajadores. En 2006 ya había más de 800 empresas chinas operando en 49 de los 54 países de África; de ellas, 480 estaban vinculadas a proyectos conjuntos con empresas africanas (Broadman, 2006, p. 6). En el período 1998-2012, la inversión china en África incluía alrededor de 2000 empresas chinas, invirtiendo en los mismos 49 países africanos (Dollar, 2015). En 2017 se contabilizaron más de 10000 empresas privadas chinas operando en ese continente (Consultancy, 2017). Esto es indicativo de los grandes intereses chinos en África, centrados principalmente en la explotación de los recursos naturales a cambio de generar infraestructura y conectividad a los Estados africanos.

Aunque Estados Unidos y la Unión Europea continúan dominando la inversión extranjera directa (IED) en África, el auge de China como socio inversionista en el continente africano es contundente. Solo entre 2003 y 2011 el flujo de inversión china creció más de 30 veces, mientras que el de Estados Unidos se incrementó apenas en una tercera parte. Esto significa una fuerte competencia entre Estados Unidos y China por la inversión extranjera directa en África. La figura 5 es ilustrativa al respecto. 
Figura 5. Inversión extranjera directa de Estados Unidos y de China en África

U.S. FDI stock in Africa

Compared to China, in billion U.S. dollars

80

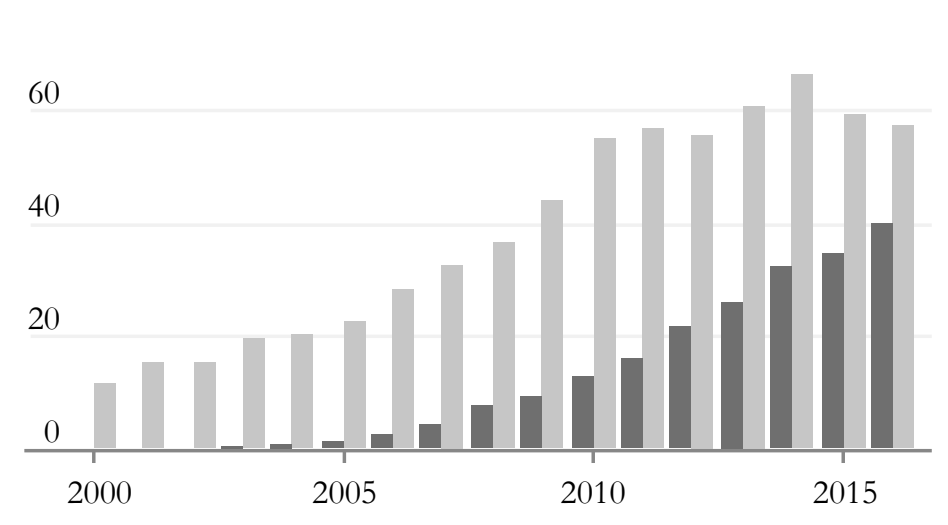

Fuente: CARI, Johns Hopkins School of Advanced International Studies (2016). Recuperado de https:// fingfx.thomsonreuters.com/gfx/editorcharts/CHINA-AFRICA/0H0014BSP20X/index.html

En el contexto de continentes y subcontinentes de destino de la IED, la RPCh en materia de inversión extranjera directa otorga un rol protagónico a África, especialmente al África subsahariana. Los principales destinos de las inversiones chinas en África incluyen Sudáfrica, Nigeria, Zambia, Argelia, Sudán y Angola. El stock de inversión extranjera directa en estos países representa más del 50\% de la inversión total en África. Para autores como Chris Alden, China es el primer inversionista en África desde 2004. Klaver y Trebilcock (2011) lo aseveran y señalan siete formas en que la inversión china contribuye al crecimiento de África: la demanda de recursos aumenta los precios de los commodities; muchos países africanos carecen de la capacidad de extraer sus propios recursos y China contribuye a mejorar dicha capacidad; la contribución china más significativa al desarrollo africano es sin duda la infraestructura; la inversión china tiene potencial para desarrollar el sector manufacturero de África; la inversión china crea empleo; la RPCh mejora el acceso de África al mercado chino al reducir los aranceles chinos; y la IED china beneficia a los consumidores africanos al reducir los precios de los productos manufacturados y los alimentos (Donou-Adonsou \& Lim, 
2018, pp. 65-66). En tal contexto, la asistencia médica se constituye en el mayor orgullo de la asistencia china en África. Entre 1963 y 2005, la RPCh despachó más de 15000 médicos a 47 países, para tratar cerca de 170 millones de personas en África (Dongkai \& Wen, 2006, p. 4).

En el marco de la Iniciativa de la Franja y la Ruta (Belt \& Road Initiative, BRI), los acuerdos y los compromisos fundados en créditos aportados por China se han incrementado notablemente. No son pocos los Estados más vulnerables a contraer deudas difíciles de pagar en África. Suman 17 y son Bahrein, Djibouti, Egipto, Etiopía, Irán, Irak, Israel, Jordania, Kenia, Kuwait, Líbano, Omán, Qatar, Arabia Saudita, Siria, Emiratos Árabes Unidos y Yemen. De ellos el caso más preocupante es Djibouti, que podría sufrir muy serios problemas de deuda debido a la futura financiación relacionada con el BRI. La evaluación más reciente del FMI destaca la naturaleza extremadamente arriesgada del programa de préstamos de Djibouti, y señala que en solo dos años la deuda externa pública ha aumentado del $50 \%$ al $85 \%$ del PIB, el más alto de todos los países de bajos ingresos. Gran parte de la deuda consiste en deuda pública garantizada por el gobierno y se debe a China Exim Bank. Según múltiples informes, China ha proporcionado casi 1400 millones de dólares de financiación para los principales proyectos de inversión de Djibouti, equivalente al 75\% del PIB de Djibouti (Downs \& Becker, 2017). Los proyectos futuros incluyen al menos dos nuevos aeropuertos, un nuevo puerto en Ghoubet, una terminal petrolera y una carretera con peaje (SAIS-CARI, 2018).

Los motivos de interés de China en países que no son ricos en recursos minerales como Djibouti y Etiopía se deben a su ubicación geoestratégica en el marco de la ruta de seda marítima china. Se trata de puntos de conexión estratégicos para la RPCh y sus rutas marítimas. Son punto de contacto crucial para penetrar tanto el África subsahariana como el Magreb. Así mismo, su ubicación frente a la península arábiga permite estrechar el vínculo con países del golfo Pérsico, donde están los más grandes productores de petróleo. Y en particular Djibouti es paso obligado al atravesar el mar Rojo para llegar al Mediterráneo. Djobouti es un paso vital para que China pueda asegurarse el suministro de petróleo, tanto el procedente de África 
como el de países de la península arábiga. Esto explica el interés chino en haber creado allí una base militar.

La IED china en países de África puede, además de casos como el de Djibouti, proporcionar pocos aportes en transferencia tecnológica, de habilidades y en empleo, además de desindustrializar a países de África, dado que la manufactura africana es débil y las empresas africanas no compiten. A su vez, las inversiones y los préstamos realizados al continente africano han sido fuertemente criticados, porque se desvían de la 'buena práctica' establecida por la OCDE en cuanto al impacto ambiental potencial, así como por la ausencia de la exigencia de informes a las empresas chinas. Igualmente, los locales se han quejado de la práctica de utilizar mano de obra china para proyectos de construcción, negando así las posibilidades de empleo para la población africana. Además, subsiste la preocupación de que las obras de infraestructura construidas con capital chino se hayan inflado en precio y que estas inversiones no obtengan el rendimiento estimado inicialmente, el cual es necesario que estos países obtengan para poder pagar las deudas adquiridas con la RPCh.

\section{Ayuda militar a África}

El incremento en la venta de armas constituye un aspecto relevante de las relaciones sino-africanas, especialmente con gobiernos amenazados por guerras civiles, movimientos insurgentes o por movimientos de oposición interna. En 2003, China ya duplicaba a Gran Bretaña en la venta de armas al África con cifras cercanas a los 1300 millones de dólares, pero bastante inferiores a las de Rusia, el primer exportador de armas al continente, con 7600 millones de dólares (Alden, 2008, p. 88). El armamento chino ha sido crucial en el desarrollo de algunos de los conflictos africanos más sangrientos, en particular en el Cuerno de África, donde décadas de confrontación bélica tanto en Etiopía como en Sudán han dado lugar a la creación de un amplio mercado para los traficantes de armas. Los fabricantes de armamentos chinos han puesto especial atención a regímenes considerados 'parias', como Sudán y Zimbabue, cuyos gobiernos tienen establecida como ilegal la compra 
de armamento a fuentes occidentales. Empresas de armas chinas como Norinco se encuentran instaladas en África. La empresa Norinco es en realidad un conglomerado de empresas que producen, de una parte, tanques, armas de artillería, municiones, armamento aéreo y naval, entre otros; y, por otra parte, está vinculada con las industrias del petróleo, minería, generación de energía eléctrica, vías férreas, ingeniería, vehículos, explosivos y productos fotoeléctricos, y ha contratado un gran número de obras que incluyen metros, vías férreas eléctricas, plantas de energía, transmisión de energía, vías y puentes en Asia, África, Medio Oriente y otras regiones. Norinco tiene tan diversificadas sus actividades al punto de que, en países como Etiopía, además de suministrar equipos militares, han llevado a cabo proyectos de ingeniería civil como la construcción de carreteras y presas (Norinco, 2016). El Ejército Popular de Liberación (EPL) dividió cinco cuerpos (espacio, aeronáutica, industria naval, armas convencionales y nucleares), "formando entonces diez empresas distintas... Norinco, Xinxing Corporation ${ }^{8}$ son nombres que circulan por toda África” (Serge \& Beuret, 2009, p. 138).

En los últimos años de la década de 1990, China envió cargamentos de armas ligeras y municiones vía Dar es Salaam al conflicto de la República del Congo, al tiempo que el armamento chino era también utilizado en la guerra civil de Sierra Leona, en la confrontación bélica entre Etiopía y Eritrea, y, posteriormente, en los conflictos de Darfur y el Chad. Nigeria compró doce reactores y misiles Shenyang que los chinos vendieron con el compromiso de formar técnicos nigerianos en operaciones por satélite. Dicho acuerdo se realizó asociado a la adjudicación de contratos petrolíferos a China en 2005 y 2006 (Alden, 2008, p. 34).

\footnotetext{
8 Fundada en 1989, Xinxing Corporation es otra gran compañía militar china. Tiene dos filiales de construcción conocidas: China Xinxing Construction \& Development General Corporation, y China Xinxing Baoxin Construction Corporation. Ambas construyen viviendas y otras obras como carreteras, instalaciones eléctricas y mecánicas, bases y cimientos, decoración arquitectónica, estructuras de acero y diseños de muros cortina. La compañía tiene tentáculos también en finca raíz, comercio, petróleo, minería, logística, industria farmacéutica, carbón y la industria de hierro, entre otras áreas. Recuperado de http://www. xxg.com.cn/english/tabid/408/language/zh-CN/Default.aspx
} 
La Guerra de Darfur a nivel internacional se ha reconocido como el mayor genocidio en lo que va corrido del siglo XXI. ${ }^{9}$ Las milicias árabes de los Janjaweed en su lucha contra el grupo rebelde Sudan People's Liberation Movement (SPLM) han generado todo tipo de actos de intolerancia y discriminación contra la población civil musulmana no árabe (Hannibla, 2008). La postura china frente al conflicto se ha justificado en el principio de no intervención en asuntos internos. No obstante, la posición de Beijing frente a la Guerra de Darfur ha sido ambigua desde tres perspectivas: su postura en el Consejo de Seguridad como miembro permanente no ha sido condenatoria de las violaciones a los derechos humanos en Sudán; su intervención e interés en la industria petrolífera sudanesa es evidente; tres fábricas chinas de armas se instalaron en Sudán y se utilizan para este país y su vecina Uganda. Igualmente, las preocupaciones sobre el impacto de algunos de los acuerdos de Beijing en materia militar en la región se han intensificado, como es el caso de Djibouti, que hoy día es altamente dependiente de la financiación china después de que la RPCh abrió su base militar en ese país del Cuerno de África en 2017.

China suscribe acuerdos militares con países de África y tiene a la vez en ellos a importantes clientes para la venta de armas, cuyos destinatarios son grupos legales e ilegales, mientras en su discurso se centra en la no injerencia en asuntos internos de otros Estados,

\footnotetext{
9 En Sudán conviven más de 50 etnias que tienen influencia tanto del mundo árabe como africano, el $70 \%$ de la población es islámica y la restante pertenece a la raza negra animista o cristiana. La diversidad étnica-religiosa, sumada a la lucha por el espacio, profundizó las divergencias entre los árabes musulmanes y los negros cristianos desatando la guerra civil entre el norte árabe-musulmán y el sur negro-cristiano animista (1960). Darfur es una de las 17 divisiones administrativas de la República de Sudán, es la región del este fronteriza con Chad, población principalmente negra musulmana no árabe. Los antecedentes que suscitan el conflicto se trazan bajo la línea de fricción entre el mundo árabe y el África negra, y la posibilidad de un replanteamiento del sistema socioeconómico-político. Ante este escenario, se formaron diferentes grupos rebeldes que desafiaron al Frente Nacional Islámico (NIF) del gobierno. La crisis de Darfur fue gestada desde 1972, pero se exacerbó en febrero de 2003 cuando los grupos rebeldes del sur, como el Sudan People's Liberation Movement (SPLM), comenzaron una lucha abierta para resguardar a la población de Darfur de la política de limpieza étnica, a la vez que buscaron defender sus derechos frente al Estado de Sudán. En respuesta, Jartum utilizó tanto sus fuerzas militares como las acciones de la milicia árabe Janjaweed (Barros, 2007; Madut Jok, 2015).
} 
lo que entra en abierta contradicción con la realidad de la presencia china en ese continente. A su vez, la RPCh construye bases militares con respaldo de Estados como Djibouti, generando cuestionamientos sobre la invasión a la soberanía nacional de ese país africano.

En contraste con todo lo anterior, y de manera paradójica, China participa en las misiones de paz respaldadas por la ONU en África, como en Liberia, República del Congo y en el propio Sudán. La mayor parte de las tropas de paz chinas en el extranjero ${ }^{10}$ están localizadas en África, lo que convierte a la RPCh en el primer país que contribuye a las misiones de paz entre los miembros permanentes del Consejo de Seguridad de las Naciones Unidas.

\section{Conclusión}

Desde la Conferencia de Bandung de 1955, pasando por las posturas no comprometedoras de la RPCh en las votaciones de la ONU, junto con sus crecientes intereses económicos que comprometen los recursos naturales de países africanos y sumados al apoyo militar hacia actores legales e ilegales dentro de Estados de ese continente, China se ha perfilado como un actor muy dinámico que ha ido logrando maximizar su poder en el continente africano, pero entrando en clara y abierta contradicción con su defensa férrea de no tener injerencia en asuntos internos de otros Estados. Así, China ha venido proyectando sus relaciones estratégicas con Estados africanos, que ha convertido en aliados en diferentes ámbitos. De una parte, son piezas fundamentales para la toma de decisiones cruciales y a favor de China en escenarios multilaterales como las Naciones Unidas.

Por otra parte, en un mundo en desarrollo que ha tenido en términos globales, en lo que va corrido del siglo actual, un crecimiento estable y que se proyecta con amplios horizontes de expansión de su mercado

\footnotetext{
10 Según estadísticas de las Naciones Unidas, en la actualidad la RPCh tiene 3045 efectivos en las tropas de paz de la ONU. Recuperado de http://www.un.org/en/peacekeeping/ resources/statistics/contributors.html
} 
laboral y de consumo, al punto de que está desplazando el rol hegemónico de las economías de países industrializados, numerosos países africanos destacan por el ritmo de crecimiento de sus economías. En tal sentido, evidencian un gran potencial de crecimiento económico, lo cual se suma al capital diplomático que China construyó con ellos desde la Guerra Fría a través del apoyo a guerras de liberación nacional y contra el colonialismo, constituyéndose así en fuertes aliados frente al cubrimiento de necesidades centrales para China, como el requerimiento de materias primas en grandes volúmenes, donde el petróleo ha ocupado un papel protagónico y la inversión china crece de manera consistente en el tiempo. A ello se suman los créditos chinos a Estados que, como Djibouti, corren el riesgo de quedar envueltos en una relación muy asimétrica y altamente dependiente de la potencia china, continuando así en condiciones difíciles de superar en materia de desarrollo.

Otro ámbito de la relación entre la RPCh y los países africanos se centra en la ayuda prestada por China en materia militar, donde los intereses chinos confluyen con los de diversos actores políticos y militares, dando lugar a una relación mutuamente beneficiosa pero que atenta contra la vida de millones de civiles atrapados en medio de actores y conflictos estatales e interestatales. Entre tanto, en su interés por dar forma a la nueva ruta de seda china marítima, China ha demostrado una hábil pericia para blindar sus relaciones políticas con apoyo militar, lo cual le genera alianzas estratégicas para el largo plazo.

La relación de China con países de África se ha constituido en un laboratorio de experimentación en muy diversos ámbitos que, a cambio de evidenciar una postura congruente con su discurso de no injerencia en asuntos domésticos de otros Estados, le asegura a China jugar un rol central y determinante para el futuro de África.

\section{Referencias}

(21-31 de octubre de 2007). China in Africa Digest.

(April 29, 2011). The 1955 Bandung Conference and its present significance. The Jakarta Post. Available from http:/ / www.thejakartapost.com/ 
news /2011/04/29/the-1955-bandung-conference-and-its-presentsignificance.html\#sthash.4sexJbrX.dpuf

(2018). China's investments in Africa. Reuters. Available from https:/ fingfx. thomsonreuters.com/gfx/editorcharts/CHINA-AFRICA/0H0014BSP20X/ index.html

Al Jazeera. (2018). China's Xi offers \$60bn in financial support to Africa. Available from https://www.aljazeera.com/news/2018/09/china-xi-offers60bn-financial-support-africa-180903100000809.html

Alden, C. (2008). China en África. Barcelona: Intermon Oxfam.

Alden, C., Large, D. \& Oliveira, R. S. (2008). China returns to Africa: a rising power and a continent embrace. London: Hurst.

Anshan, L. (2006). Lun Zhongguo Jueqi’ Yujingzhong De Zhongfei Guanxi [Sino African relations under the "China Rising" discourse]. Shijie Jingï Yu Zhengzhi, (11).

Arenal, C. del. (1990). Introducción a las relaciones internacionales. Madrid: Tecnos. Associated Press (AP). (21 de mayo de 1965), citado por Van Ness, P. (1970). Revolución y politica exterior china. El apoyo de Beïing a las guerras de liberación nacional. Buenos Aires: Ed. Libera.

Barros, C. (2007). Las grandes potencias pelean por la riqueza de Africa. Recuperado de http://www.webislam.com/articulos/33872-las_grandes_potencias_pelean_por_la_riqueza_de_africa.html

Booth, K. \& Trood, R. (1999). Strategic cultures in the Asia-Pacific region. New York: St. Martin's Press, citado por Andornino, G. B. (2010). China and global governance: ¿status quo power or challenge to the global order? In S. Breslin, Handbook of China's international relations. London: Routledge.

Bradley, M. (2010). Decolonization, the Global South, and the Cold War, 1919-1962. In M. P. Leffler \& O. A. Westad (Eds.), The Cambridge history of the Cold War. Vol. I (pp. 464-485). Origins. Cambridge,

Breslin, S. (2010). Handbook of China's international relations. London: Routledge.

Broadman, H. (2006). Africa's silk road: China and India's new economic frontier. Washington, D.C.: World Bank.

Consultancy. (2017). 10000 firms in Africa as Ministry of Commerce underes-timates number. Available from https://www.consultancy.uk/news/13690/10000chinese-firms-in-africa-as-ministry-of-commerce-underestimates-number 
Cooley, J. K. (1965). East wind over Africa: red China's African offensive. New York: Walker.

CRI. (18 de septiembre de 2013). El desarrollo diplomático de China. China Radio Internacional. Recuperado de http://espanol.cri. cn/1161/2013/09/18/1s290110.htm

China Civil Engineering Construction Corporation. (2007). Recuperado de http://www.ccecc.com.cn/2006-11/200611473046.htm; http:// www.ccecc.com.cn/2007-1/200712282439.htm

Deng, Y. (2008). China's struggle for status. The realignment of international relations. Cambridge University Press.

Dollar, D., Tang, H. \& Chen, W. (2015). Why is China investing in Africa? Evidence from the firm level. Washington: George Washington UniversityInternational Monetary Fund.

Dongkai, L. \& Wen, Z. (2006). Zhongguo Long Yu Feizhoushi Gongwu [The Chinese dragon and African lion dancing together]. RMRB.

Donou-Adonsou, F. \& Lim, S. (2018). On the importance of Chinese investment in Africa. Science Direct, Review of Development Finance, 8, 63-73. https://doi.org/10.1016/j.rdf.2018.05.003

Downs, E. S. \& Becker, J. (September, 2017). China's presence in Djibouti is not a national security threat-yet. The National Interest. Recuperado de: https://nationalinterest.org/feature/chinas-presence-djiboutinot-national-security-threat $\% \mathrm{E} 2 \% 80 \% 94$ yet- 22498

Edoho, F. M. (2011). Globalization and marginalization of Africa: contextualization of China-Africa relations. Africa Today, 58(1), 103-124.

Fok, D. (s. f.). The emergence of a superpower: China's UN policies from 1971 to present. Duke East Asia Nexus. Available from http://www. dukenex.us/the-emergence-of-a-superpower-chinas-un-policies-from1971-to-present.html

Foot, R. (2003). The UN System's contribution to Asia-Pacific security architecture. The Pacific Review, 16(2), 207-230.

Garver, J. W. (2016). China's quest: the history of the foreign relations of the people's Republic of China. Oxford University Press.

Gernet, J. (2005). El mundo chino. (Traducción de Dolors Folch). Barcelona: Crítica.

Global Policy Forum. (2008). Changing patterns in the use of the veto in the Security Council. Available from https://www.globalpolicy.org/component/ content/article/102/32810.html 
Hodzi, O. (2018). China and Africa: economic growth and a non-transformative political elite. Journal of Contemporary African Studies, 36(2), 191-206. https://doi.org/10.1080/02589001.2017.1406191

$\mathrm{Hu}, \mathrm{J}$. (noviembre, 2006). Speech at the opening ceremony of the Beijing summit of China-African Cooperation Forum. RMRB.

Hu, Y. (1982). Create a new situation in all fields of socialist modernization. Report to the XII National Congress of the Communist Party of China. Beijing Review, 37(25), 1-46.

Jiang, Z. (2002). Jiang Zemin's report at $16^{\text {th }}$ Party Congress. Available from https://www.fmprc.gov.cn/mfa_eng/topics_665678/3698_665962/ t18872.shtml

Kissinger, H. (2012). China. New York: Penguin Books.

Madut Jok, J. (2015). Sudan: race, religion and violence. India: On World Publications.

Ministry of Foreign Affairs, Republic of Indonesia. (1955). Final communiqué of the Asian-African Conference of Bandung (24 April 1955). In Asia-Africa speak, from Bandung. Djakarta. Available from http:// franke. uchicago.edu/Final_Communique_Bandung_1955.pdf

New York Times, (16 de agosto de 1965). New York, p. 8.

New York Times. (10 de junio de 1966). New York, p. 20.

Norinco. (2016). Recuperado de http:/ /www.norinco.com/GB/61/91/94/ index.html

ONU. (2015). Security Council veto. Available from http://research.un.org/ en/docs/sc/quick/veto

Park, Y. J., Lampert, B. \& Robertson, W. (2016). Editorial: China's impacts on Africa's development. African Review of Economics and Finance, 8(1), 3-11.

People's Daily. (2002), citado por Duggan, N. \& Naarajarvi, T. (2015). China in global food security governance. Journal of Contemporary China, 24(95), 947.

Pontemayor, F. \& Mothe, S. (2016). In Park, Y. J., Lampert, B. \& Robertson, W. Editorial: China's impacts on Africa's development. African Review of Economics and Finance, 8(1).

PRC. (2005). Permanent mission at the UN Position paper of the people's Republic of China on the United Nations reforms'. Available from www.china-un.org/ eng/zt/gaige/t199101.htm 
PRC. (2015). People's Republic of China mission to the United Nations. Unite as one and work for a bright future. Available from http:/ / www.un.org/ga/64/ generaldebate/pdf/CN_en.pdf

PwC. (2017). The world in 2050. The long view: how will the global economic order change by 2050? UK: Pricewaterhouse Coopers.

SAIS-CARI. (2018). China-Africa Research Initiative. Database. John Hopkins School of Advanced International Studies. Available from http:// www.sais-cari.org/

Scott, D. (2010). China and the "responsibilities" of a "responsible" power. The uncertainties of appropriate power rise language. Asia-Pacific Review, 17, 72-96.

Schaufelbuehl, J. M., Bott, S., Hanhimáki, J. \& Wyss, M. (2015). Non-alignment, the third force, or fence-sitting: independent pathways in the Cold War. The International History Review, 37(5), 901-911.

Serge, M. \& Beuret, M. (2009). China en África. Pekin a la conquista del continente africano. Barcelona: Alianza Editorial.

Shinn, D. H. (2019). China's economic impact in Africa. In Oxford research encyclopedia of politics. USA: Oxford University Press. https://doi. org/10.1093/acrefore/9780190228637.013.831

State Council. (2005). White paper on China's peaceful development road. Beijing. Available from http://english.gov.cn/links/whitepapers.htm

Sun, I. Y., Jayaram, K. \& Kassiri, O. (2017). Dance of the lions and dragons: how are Africa and China engaging, and how will the partnership evolve? McKinsey \& Company.

Taylor, V. I. (2002). Taiwan's foreign policy in Africa: the limits of dollar diplomacy. Journal of Contemporary China, 11(30).

Tieh, S. (2004). China in the UN, united with other nations? Stanford Journal of East Assian Affairs, 4(1), 2004. Available from http:/ / web.stanford. edu/group/sjeaa/journal41/china1.pdf

Travis, H. (2008). Genocide in Sudan: the role of oil exploration and the entitlement of the victims to reparations. Arizona Journal of International and Comparative Law, 25(1), 1-73.

Van Ness, P. (1970). Revolución y politica exterior china. El apoyo de Beijing a las guerras de liberación nacional. Buenos Aires: Ed. Libera.

Wang, J. S. (2004). China's petroleum security and geopolitics. Resources and industries. 
World Bank. (2013). China 2030 building a modern, harmonious, and creative society. Recuperado de http://www.worldbank.org/content/dam/ Worldbank/document/China-2030-complete.pdf

World Bank. (2016). GDP ranking. Available from http://data.worldbank. org/data-catalog/GDP-ranking-table

World Bank. (2018). Global economic prospects 2018. Washington: The World Bank.

World Bank. (2019). Global economic prospects 2019. Washington: The World Bank.

Xi, J. (2014). Xi's speech at 'Five Principles of Peaceful Coexistence' anniversary. At meeting marking the $60^{\text {th }}$ anniversary of the initiation of the Five Principles of Peaceful Coexistence, 28 June 2014. Available from http://www.china.org.cn/world/2014-07/07/content_32876905.htm

Xinhua. (2003). Ministerial meeting of China-Africa Forum ends with adoption of action plan. Xinhuanet, citado por Deng, Y. (2008). China's struggle for status. The realignment of international relations. Cambridge University Press.

Zheng, B. (2005). Ten views on China's development road of peaceful rise and Sino European relations. Conferencia presentada en el Foreign Policy Center, Londres.

Zweig, D. \& Jianhai, B. (2005). The foreign policy of a resource hungry State. Foreign Affairs, 84(5), 25-38. https:/ / doi.org/10.2307/20031703 